УДК 621.391:519.724

\title{
КРИТЕРИЙ МИНИМУМА СРЕДНЕГО ИНФОРМАЦИОННОГО ОТКЛОНЕНИЯ ДЛЯ РАЗЛИЧЕНИЯ СЛУЧАЙНЫХ СИГНАЛОВ С БЛИЗКИМИ ХАРАКТЕРИСТИКАМИ
}

\author{
В. В. САВЧЕНКО \\ Нижегородский государственный лингвистический университет, \\ Россия, Нижний Новгород, 603155, ул. Минина, 31 а
}

\begin{abstract}
Аннотация. Рассмотрена задача различения случайных сигналов с близкими спектрально-корреляционными характеристиками. Для ее решения предложен критерий минимума среднего значения дивергенции принимаемых гипотез относительно истинного распределения вероятностей в информационной метрике Кульбака-Лейблера. С использованием данного критерия синтезирован оптимальный алгоритм, благодаря которому достигается гарантированный выигрыш по эффективности при различении случайных сигналов близкой структуры. Рассмотрен пример его реализации в задаче автоматического распознавания речи на базовом, фонетическом уровне обработки сигналов. Получены оценки его эффективности. Теоретические оценки эффективности подтверждены результатами эксперимента. При этом применена авторская информационная система специального назначения. На основании полученных результатов даны рекомендации по практическому применению предложенного критерия в задачах статистической обработки сигналов, где возникает проблема проверки близких статистических гипотез.
\end{abstract}

Ключевые слова: случайный сигнал; различение сигналов; проверка статистических гипотез; критерий максимума правдоподобия; проблема близких гипотез; теоретико-информационный подход

\section{ВВЕДЕНИЕ}

Случайный сигнал - универсальная математическая модель материального переносчика информации, в которой наиболее полно отображаются наблюдаемые на практике искажения принимаемых сообщений: за счет нестабильности характеристик приемопередающего тракта, влияния случайных помех и по другим известным в радиотехнике причинам [1-5]. Поэтому такая модель находит широкое применение в самых разных задачах обработки информации. К числу наиболее актуальных из них относится задача различения случайных сигналов [6-9].

Стандартная формулировка такой задачи описывается в терминах теории проверки ста- тистических гипотез $[10,11]$. Среди ее критериев долгие годы доминирует критерий максимума правдоподобия [12], особенно при многоальтернативной постановке задачи. Однако его практическое использование наталкивается на проблему проверки близких альтернативных гипотез [13-16], которая часто является непреодолимым препятствием на пути к различению сигналов с высокой точностью.

Примером может служить задача автоматического распознавания речи (АРP) на базовом, фонетическом уровне обработки сигналов $[17,18]$, где близкие по восприятию речевые единицы характеризуются близостью и в теоретико-информационном смысле. В результате, отдельные пары фонем теория АРР относит к проблемным звукам речи [19]. Поэтому пред- 


\section{БИБЛИОГРАФИЧЕСКИЙ СПИСОК}

1. Колчев, А.А.; Недопекин, А.Е. “Использование модели смеси вероятностных распределений при обнаружении сигналов радиофизического зондирования," Известия вузов. Радиоэлектроника, Т. 59, № 8, C. 44-51, 2016. DOI: 10.20535/S0021347016080057.

2. Скачков, В.В.; Чепкий, В.В.; Братченко, Г.Д.; Ефимчиков, А.Н. “ЭНнропийный подход к исследованию информационных возможностей адаптивной радиотехнической системы при внутрисистемной неопределенности," Известия вузов. Радиоэлектроника, Т. 58, № 6, C. 3-12, 2015. DOI: 10.20535/S002134701506 $\underline{0011}$.

3. Продеус, А.Н.; Дидковский, В.С. “Объективное оценивание качества алгоритмов радикального шумоподавления," Известия вузов. Радиоэлектроника, Т. 59, № 11, С. 37-46, 2016. DOI: $10.20535 / \mathrm{S} 00213$ 47016110042.

4. Савченко, В.В. “Повышение помехоустойчивости системы голосового управления робототехникой на основе метода фонетического декодирования слов," Радиотехника и электроника, Т. 61, № 12, С. 1196-1201, 2016. DOI: 10.7868/S0033849416120238.

5. Савченко, В.В. "Оценка фонетического качества речи на основе теоретико-информационного подхода," Радиотехника и электроника, Т. 63, № 1, С. 60-64, 2018. DOI: $\underline{\text { 10.7868/S0033849417010089. }}$.

6. Акимов, А.В.: Сирота, А.А. "Синтез и анализ алгоритмов распознавания цифровых сигналов в условиях деформирующих искажений и аддитивных помех," Известия вузов. Радиоэлектроника, Т. 60, № 10, C. 592-604, 2017. DOI: $10.20535 / \mathrm{S} 0021347017100041$.

7. Неуймин, А.С.; Жук, С. Я. “Адаптивное последовательное обнаружение траектории цели с использованием решающих статистик отметок при неизвестном отношении сигнал-шум," Известия вузов. Радиоэлектроника, Т. 59, № 8, C. 33-43, 2016. DOI: $\underline{10.20535 / \mathrm{S} 0021347016080045 .}$. 
8. Савченко, В.В. “Решение проблемы множественных сравнений в задачах автоматического распознавания сигналов на выходе тракта речевой связи," Электросвязь, № 12. С. 22-27, 2017.

9. Savchenko, A. V. "Clustering and maximum likelihood search for efficient statistical classification with medium-sized databases," Optimization Lett., Vol. 11. No. 2, P. 329-341, 2017. DOI: 10.1007/s11590-015-0948-6.

10. Леман, Э. Проверка статистических гипотез. М.: Наука. ГРФМЛ, 1979. 408 с.

11. Боровков, А.А. Математическая статистика. Санкт-Петербург: Лань, 2010. 704 с.

12. Левин, Б.Р. Теоретические основы статистической радиотехники. Изд. 3-е, перераб. и доп. М.: Радио и связь, 1989. 656 с.

13. Lehmann, E. L.; Romano, J. P. Testing Statistical Hypotheses. 3rd ed. New York: Springer, 2005. DOI: 10.1007/0-387-27605-X.

14. Рыбин, А.И.; Нижебецкая, Ю.Х. “Анализ подобия и различия образов с использованием нормального ортогонального преобразования," Известия вузов. Радиоэлектроника, Т. 53, № 3, С. 58-64, 2010. URI: http://radio.kpi.ua/article/view/S00213470100300 $\underline{76}$.

15. Попов, А. А. "Теорема отсчетов для сигналов пространства, построенного на обобщенной булевой алгебре с мерой," Известия вузов. Радиоэлектроника, T. 53, № 1, C. 31-39, 2010. URI: http://radio.kpi.ua/ article/view/S002134701001005X.

16. Лемешко, Б. Ю.; Лемешко, С. Б.; Постовалов, С. Н. "Мощность критериев согласия при близких альтернативах.” Измерительная техника, № 2, С.22-27, 2007. DOI: $10.1007 / \mathrm{s} 11018-007-0036-0$.

17. Савченко, В.В.; Савченко, А.В. “Теоретико-информационное обоснование и анализ эффективности метода фонетического кодирования-декодирования в задаче автоматического распознавания речи,"
Радиотехника и электроника, Т. 61, № 4, С. 373, 2016. DOI: $10.7868 / \mathrm{S} 0033849416040112$.

18. Жук, С. Я.; Ковалев, В.И. “Алгоритм совместной фильтрации речевого сигнала и оценки ошибки синхронизации в двухканальной измерительной системе," Известия вузов. Радиоэлектроника, Т. 43, № 6, C. 36-44, 2000. URI: http://radio.kpi.ua/article/view/S00 21347000060078 .

19. Savchenko, A. V. "Sequential three-way decisions in efficient classification of piecewise stationary speech signals," Int. Joint Conf. Rough Sets, Vol. 10314, P. 264-277, 2017. DOI: 10.1007/978-3-319-60840-2_19.

20. Kullback, S. Information Theory and statistics. New York: Dover Publications, 1997. 399 p.

21. Савченко, В.В. "Принцип минимакса энтропии в задачах статистической классификации," Известия вузов. Радиоэлектроника, Т. 33, № 12, С. 35-39, 1990.

22. Zhou, D.; Platt, J. C.; Basu, S.; Mao, Yi. "Learning from the Wisdom of crowds by minimax entropy," Proc. of 25th Int. Conf. on Neural Information Processing Systems, 3-6 Dec. 2012, Lake Tahoe, Nevada, USA. Vol. 2, P. 2195-2203.

23. Марпл, С.Л.-мЛ. Цифровой спектральный анализ и его приложения: Пер. с англ. М.: Мир, 1990. $584 \mathrm{c}$.

24. Былинкин, А. А.; Конов, С. Л. "Способ распознавания случайных сигналов по форме спектра,” Вoпросы защиты информации, № 2, С. 30-36, 2017. URI: https://elibrary.ru/item.asp?id=29207442.

25. Конев, А. А.; Мещеряков, Р. В.; Ходашинский, И.А. "Распознавание гласных звуков по информации о первой и второй гармонике," в сб.: Шестой междисизилинарный семинар "Анализ разговорной русской речи» (АР3-2012). Составитель: А.Л.Ронжин. С.-Пб.: Изд-во СПГУ, 2012. С. 35. 